\title{
SECHSSTELLIGE GAUSSISCHE
}

\author{
wo \\ SIEBENSTELLIGE GEMEINE \\ LOGARITHMEN \\ VUN \\ S. GUNDELFINGER
}

ZWEITE, DURCH EINE ERGÄNZUNGSTABELLE VERMEHRTE AUSGABE.

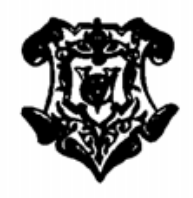

LEIPZIG

VERLAG VON VEIT \& COMP.

1902 
Alle Rechte, einschliesslich des Obersetzungsrechts, vorbehalten.

Druck von Metzger \& Wittig in Leipzig. 